\title{
A Game Theory Approach to Address Profit Conflicts in Environmental Regulation of Shale Gas Development in Chongqing of China
}

\author{
L. Liu, X. B. Jiang, X. Y. Lu, and S. Zhou
}

\begin{abstract}
The shale gas industry is growing very fast in China. Its potential environmental risks cause disputes among different stake holders. This paper used a game theory to study the choice behaviors and their impact factors of environmental regulators and production companies. The proposed model was applied to a shale gas project in Chongqing, China for demonstrating a case study in fast developing regions. It turns out that the pressure of environmental regulators is high; local residents may have the tendency to neglect the environmental risk because of economic benefits. We propose the environmental management pays more attention on heavy regulations to over-standard discharge companies and strengthen public participation by opening up more ways to participate.
\end{abstract}

Index Terms-Environmental regulators, game theory, production company, shale gas.

\section{INTRODUCTION}

With the rapid economic development, the demand for energy is growing quickly. Shale gas, as an emerging unconventional gas with huge reserves, has challenged the dominant position of the energy structure. Development of shale gas industry will not only promote local economic development and employment, but also accelerate the adjustment of energy consumption structure and guarantee the security of energy supply [1]. But the hydraulic fracturing can lead to a large amount of water resources consumption, drilling fluid leakage, water pollution, air pollution, intensifying the greenhouse effect and even causing geological hazards [2]-[8].

According to latest results of national shale gas resource evaluation from China, the terrestrial shale gas geological resource potential is a total of $134.42 \times 10^{4}$ billion $\mathrm{m}^{3}$. The recoverable resource potential is $25.08 \times 10^{4}$ billion $\mathrm{m}^{3}$ (do not include the Tibetan region) and the accumulated proven reserve is $7364 \times 10^{4}$ billion $\mathrm{m}^{3}$. The shale gas industry is

Manuscript received December 25, 2017; revised September 2, 2018 This study was supported by the Program for Changjiang Scholars and Innovative Research Team in University (IRT_17R112).

L. Liu is with State Key Laboratory of Coal Mine Disaster Dynamic and Control, and School of Resource and Environmental Science, Chongqing University, Chongqing, CO 400044, China (e-mail: zhliuli@cqu.edu.cn).

X. B. Jiang and S. Zhou are with School of Resource and Environmental Science, Chongqing University, Chongqing, CO 400044, China (e-mail:20152013060@cqu.edu.cn,676062196@qq.com).

X. Y. Lu was with Chongqing University, China, CO 400044 China. She is now with Tech and Ecology Construction Co. Ltd., Shenzhen, CO 518000, China (e-mail: 378151944@qq. com). growing very fast in China. Its potential environmental risks cause disputes among different stakeholders [4]-[6]. For example, there are conflicts of interest between companies and environmental regulators: Companies prefer to spend less money on investments for environmental protection; oppositely, regulators want companies to spend more budgets on pollutants treatment. This scenario leads to an interaction between two decision-makers with differently and potentially conflicting objectives. We need to focus on behaviours of production companies and environmental regulators, and put forward practical environmental regulation strategies. But most of the conducted researches about environmental managements on shale gas development are mainly focused on the environmental risk analysis [7]-[9]. Few researches focus on the interest conflicts among the stake holders. The aim of this paper was to use a game theory to address profit conflicts in environmental regulation of shale gas development in Chongqing of China, which demonstrated a case study in fast developing regions.

\section{COnStructions OF GAME Model}

\section{A. Assumptions}

The study is based on the hypothesis that there are only two participants -- environmental regulators and shale gas development companies and they both are rational economic people. Social image and welfare are the payoff of environmental regulators, and economic profits are the payoff of development companies.

\section{B. Payoff Matrix}

TABLE I: PARAMETERS IN THE MODEL

\begin{tabular}{|c|c|}
\hline Symbols & Notes \\
\hline$I_{e}$ & Profit of the company's over-standard emission without treatments \\
\hline$C_{e}$ & Extra cost of disposing pollutants for the production company \\
\hline$I_{g}$ & Original payoff of the environmental supervision department \\
\hline$C_{g}$ & $\begin{array}{l}\text { Special environmental regulatory fees of shale gas production } \\
\text { project }\end{array}$ \\
\hline$F$ & Fine for the companies' over-standard emission found by regulators \\
\hline$A$ & $\begin{array}{l}\text { Subsidies from environmental regulators to companies of } \\
\text { under-standard emission }\end{array}$ \\
\hline$R$ & $\begin{array}{l}\text { Bonus from higher authorities to regulators to improve } t \\
\text { heir regulatory motivation }\end{array}$ \\
\hline$D$ & $\begin{array}{l}\text { Penalty from higher authorities to regulators for their regulatory mi } \\
\text { sconduct }\end{array}$ \\
\hline$J_{g}$ & Public evaluation towards environmental regulators' activities \\
\hline$J_{e}$ & Public evaluation towards production companies' activities \\
\hline$p$ & Probability of environmental regulators taking monitoring strategy \\
\hline$q$ & Probability of the production company achieving discharge standard \\
\hline
\end{tabular}


In this study, these two players' strategies are "monitor or not to monitor" and "under- standard emission or over-standard emission". The payoff matrix and definitions of relevant parameters in the model are shown in table 1 and table 2. Payoff functions are constructed as Eqs. (1) and (2) respectively. In the Eqs. $V e$, indicates the payoffs of the production company, while $V g$, indicates the payoffs of the environmental regulators. Then according to the theory of profit-maximization, $\left(p^{*}, q^{*}\right)$ is obtained, as shown in Eqs. (3).

TABLE II: GAME PAYOFF MATRIX

\begin{tabular}{lcc}
\hline \hline $\begin{array}{l}\text { Environmental } \\
\text { regulators } \\
\text { (Player 2) }\end{array}$ & \multicolumn{2}{c}{ The shale gas production company (Player 1) } \\
\cline { 2 - 3 } & $\begin{array}{c}\text { Under-standard } \\
\text { emission(q) }\end{array}$ & $\begin{array}{l}\text { Over-standard } \\
\text { emission(1-q) }\end{array}$ \\
\cline { 2 - 3 } $\begin{array}{l}\text { Monitor(p) } \\
\text { Not to monitor } \\
(1-p)\end{array}$ & $\left(\mathrm{I}_{\mathrm{g}}-\mathrm{C}_{\mathrm{g}}+\mathrm{R}+\mathrm{J}_{\mathrm{g}}, \mathrm{I}_{\mathrm{e}}-\mathrm{C}_{\mathrm{e}}+\mathrm{A}+\mathrm{J}_{\mathrm{e}}\right)$ & $\left(\mathrm{I}_{\mathrm{g}}-\mathrm{C}_{\mathrm{g}}+\mathrm{F}+\mathrm{R}+\mathrm{J}_{\mathrm{g}}, \mathrm{I}_{\mathrm{e}}-\mathrm{F}-\mathrm{J}_{\mathrm{e}}\right)$ \\
\hline \hline
\end{tabular}

$$
\begin{gathered}
\mathrm{Ve}=\mathrm{p}\lfloor\mathrm{q}(\mathrm{Ie}-\mathrm{Ce}+\mathrm{A}+\mathrm{Je})+(1-\mathrm{q})(\mathrm{Ie}-\mathrm{F}-\mathrm{Je})\rfloor \\
+(1-\mathrm{p})[\mathrm{q}(\mathrm{Ie}-\mathrm{Ce}+\mathrm{Je})+(1-\mathrm{q})(\mathrm{Ie}-\mathrm{Je})] \\
\mathrm{Vg}=\mathrm{q}\lfloor\mathrm{p}(\mathrm{Ig}-\mathrm{Cg}+\mathrm{R}+\mathrm{Jg})+(1-\mathrm{p})(\mathrm{Ig}-\mathrm{Jg}-\mathrm{D})\rfloor \\
+(1-\mathrm{p})[\mathrm{p}(\mathrm{Ig}-\mathrm{Cg}+\mathrm{F}+\mathrm{R}+\mathrm{Jg})+(1-\mathrm{p})(\mathrm{Ig}-\mathrm{Jg}-\mathrm{D})] \\
\mathrm{p}^{*}=(\mathrm{Ce}-2 \mathrm{Je}) /(\mathrm{A}+\mathrm{F}), \\
\mathrm{q}^{*}=1-(\mathrm{Cg}-\mathrm{R}-\mathrm{D}-2 \mathrm{Jg}) / \mathrm{F}
\end{gathered}
$$

\section{CASE ANALYSIS}

\section{A. Case Description}

In this section, a shale gas project is presented to illustrate this proposed model, which is situated in Fuling Chongqing, China (the geographic location is shown in Fig. 1 and 2).

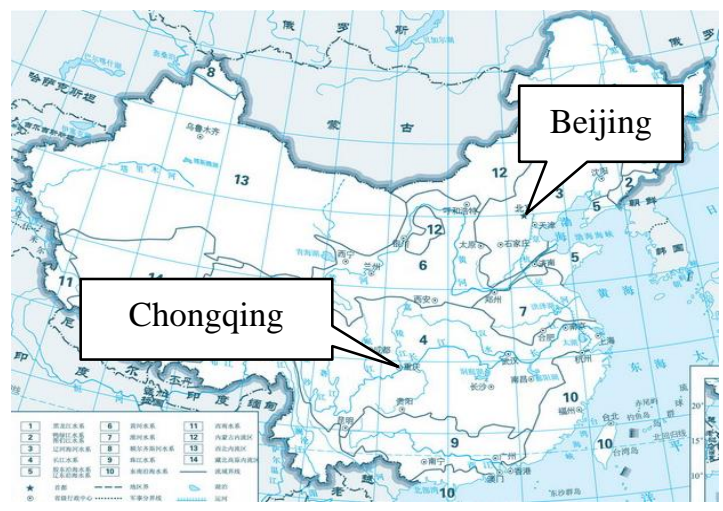

Fig. 1. The geographic position of Chongqing in China.

\section{B. Data Sources}

In this paper, study subjects include local residents, the production company (Petro China) and the environmental regulators (Chongqing Fuling District Environment Protection Bureau and the local government). We collected data by questionnaire, interview and searching online materials.
A questionnaire was designed aimed at the local residents and local workers from Petro China, including the subject's personal information, distance to the nearest shale gas well from his or her home, knowledge about this project and grades for the production company and the environmental protection department, mainly to investigate their opinions and evaluations about the shale gas development project. A hundred and twenty subjects were randomly selected, covering an area of about 2 kilometers radius from Jiaoshi Street to complete the questionnaire. 106 effective questionnaires were acquired.

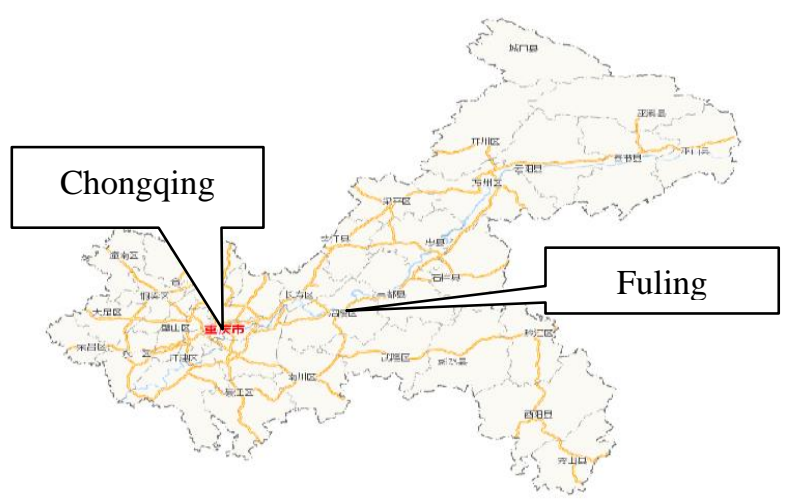

Fig. 2. The geographic position of Fuling in Chongqing.

We contacted and interviewed 13 technical or managerial staff from the production company (5) and the environmental protection department (8), to investigate some basic development and monitoring information of the shale gas project. (The production company: technical processes, pollutants and relevant treatments and cost of this development project; the environmental protection department: the frequency, measures, contents and cost of supervision, and the importance of public evaluation for both.)

We collected some supplementary material via internet to make up the data which we did not successfully acquired during the interview, due to confidentiality, namely, environmental cost, monitoring cost, monitoring contents, etc..

\section{Observations and Results}

\section{1) Residents' investigation}

Fig. 3 and 4 respectively show how subjects evaluate the production company and how education background influences their grades.

Fig. 3 shows that over $85 \%$ of subjects are clear what benefits the development has brought to them, namely promoting employment, increasing income, improving transport facilities etc.; about $47 \%$ of subjects may have a positive view, while nearly $19 \%$ of them oppositely; most subjects can point out the environmental problems of the shale gas project, including air pollution, noises, water pollution, soil contamination and others, and $9 \%$ of them have no ideas about the drawbacks.

Fig. 4 indicates that a well-educated subject is more likely to give a higher grade to companies. (In Fig. 4 and 6, the horizontal axis represents the distance to the nearest well from their home.) During the investigation, we found that 
most poorly educated residents are illiterate or unemployed homemakers and farmers, most of whom may have no appropriate access to information. Oppositely, the information channel of better-educated subjects is wider, and they understand the project more thoroughly. Hence, if companies want to improve their social reputation, they need to adopt multi-form publicity to increase local people's knowledge about the shale gas project.

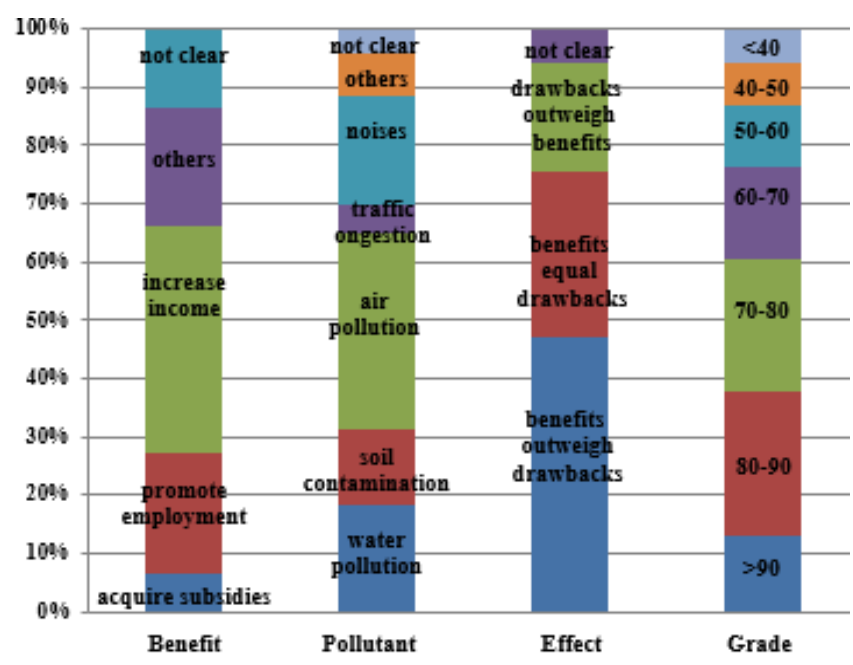

Fig. 3. Residents' evaluations on Play 1.

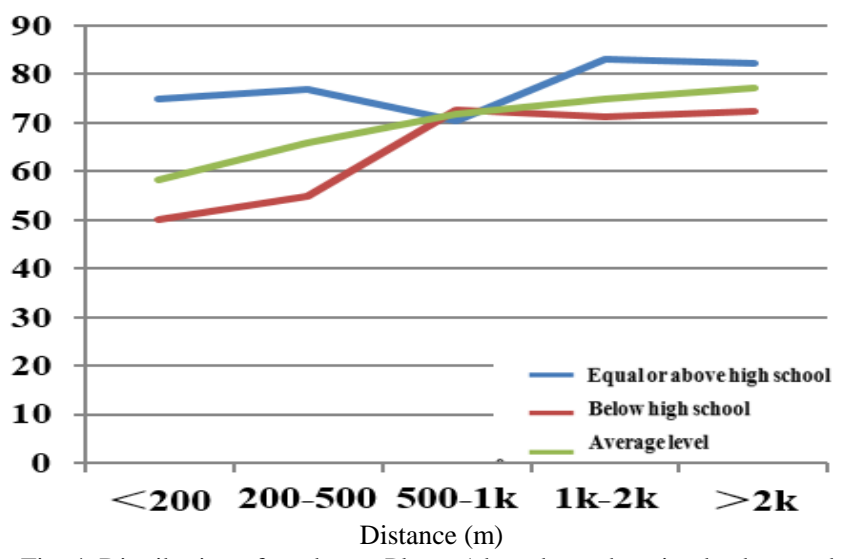

Fig. 4. Distribution of grades on Player 1 based on education background.

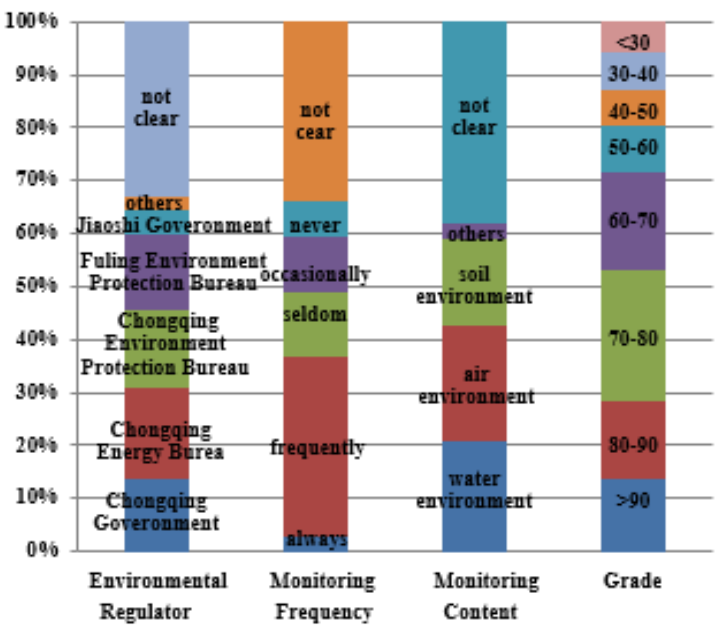

Fig. 5. Residents' evaluations on Player 2.

Fig. 5 and 6 respectively show how subjects evaluate environmental regulators and how education background influences their grades.
Fig. 5 shows that only $18 \%$ of subjects may know the environmental regulator exactly; besides, over $30 \%$ of subjects may not know the monitoring frequency; nearly $40 \%$ of subjects are likely to be confused of monitoring contents.

In Fig. 6, grades on regulators have experienced a similar tendency like those on the company. Therefore, to improve social evaluation of environmental regulators, they may need to strengthen the communication with local residents, facilitate residents' understanding of their work, and make residents more involved in the environmental management.

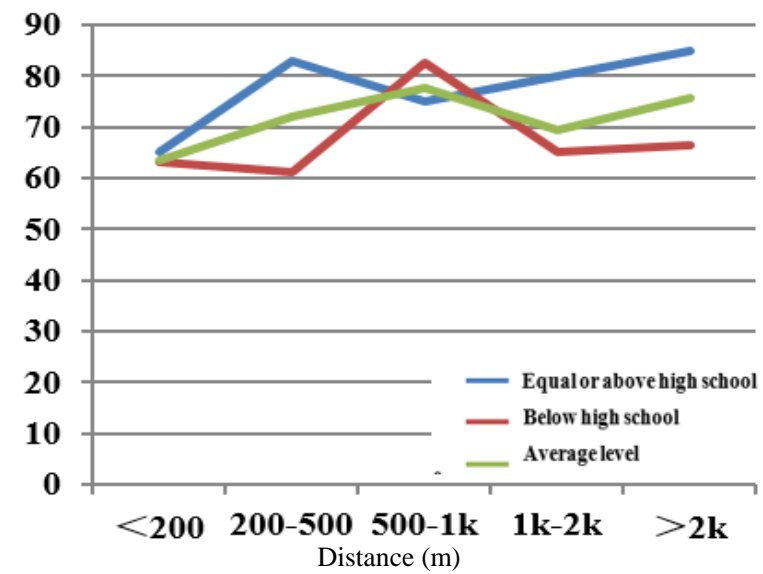

Fig. 6. Distribution of grades on Player 2 based on education background.

Local residents may be very familiar with effects of the shale gas project. However, most residents know little about environmental regulators' work, and the possible reason may be that public participation is insufficient.

\section{2) Interview analysis}

Disposal methods of fracturing fluid include recycling and pollutant degradation, and at least $20 \%$ of flowback fluid needs to be degenerated based on the existing technology. The company agrees that public evaluation is important, but they are just willing to provide $34 \%$ of environmental cost to compensate surrounding residents. Interviews of regulators show that existing regulatory system is based on "in advance, in the course and afterwards", and the frequency is arranged by reality, usually several times a week. Regulators concern about public evaluation, willing to pay about $48 \%$ of their fiscal expenditures as public warfare.

3) Outputs of the model's parameters

Specific values of the parameters are summarized in Table III.

TABLE III: PARAMETERS AND ASSIGNMENTS OF THE MODEL

\begin{tabular}{ccccc|cccc}
\hline \hline & \multicolumn{3}{c|}{ The shale gas production } & \multicolumn{5}{c}{ The environmental } \\
company & & \multicolumn{5}{c}{ regulator } \\
\hline Parameters & $\mathrm{Ce}$ & $\mathrm{Je}$ & $\mathrm{A}$ & $\mathrm{F}$ & $\mathrm{Cg}$ & $\mathrm{Jg}$ & $\mathrm{R}$ & $\mathrm{D}$ \\
Amount & $88^{[10}$ & 30 & & & & 31 & 0 & 0 \\
$\left(* 10^{4} \mathrm{CNY}\right)$ & $\mathrm{l}$ & $(34 \%)$ & 0 & 5 & 65 & $(48 \%)$ & & \\
\hline \hline
\end{tabular}

\section{Game Results and Analysis}

Then variables of $\mathrm{p}^{*}$ and $\mathrm{q}^{*}$ can be determined based on table 3. The detail calculation processes are expressed in Eqs. (4) and (5).

$\mathrm{p}^{*}=(\mathrm{Ce}-2 \mathrm{Je}) /(\mathrm{A}+\mathrm{F})=(88-2 * 30) / 5=5.6$ 


$$
\begin{aligned}
& \mathrm{q}^{*}=1-(\mathrm{Cg}-\mathrm{R}-\mathrm{D}-2 \mathrm{Jg}) / \mathrm{F} \\
& =1-(65-2 * 31) / 5=0.4
\end{aligned}
$$

Hence, when the game is balanced, the probability that environmental regulators choose to monitor the company is about 5.6, which is far beyond 1 , and the probability that the production company reaches the emission standard is only about 0.4 . That may indicate that the regulatory pressure is high, and even if the company is supervised every day, the percentage of under-standard pollutant is lower than $50 \%$.

Based on our site investigation, reasons that lead to this phenomenon may be that: Public evaluation may not play a role in companies' production activities adequately; the public cannot evaluate the shale gas project objectively, because of the lack of information and knowledge; besides, some local residents may overly focus on economic benefits rather than environment problems they cause, which may imply that local economic situation is backward, and the community's need is likely to stay on the basic physiological level; existing penalty of over-standard discharge may not have a deterrent effect on companies. Companies may be willing to accept the fine rather than increase investment in environmental measures, and these make environmental regulators suffer from heavy work pressure.

\section{E. Analysis of Game Equilibrium Variation}

From the aforementioned discussion, we may draw a conclusion that the practical supervision probability of environmental regulators does not reach the requirements when the game is balanced, and the over-discharge behavior of production companies is serious, which cannot guarantee local environmental quality. Hence, we will adjust values of parameters to convert the game equilibrium to maintain the environmental quality and reduce the pressure of environmental regulation.

\section{1) Reduce the cost of pollutants treatment and} environmental regulation.

To promote companies' under-standard emission probability (q) over $80 \%, \mathrm{Cg}$ should be reduced to $31 \%$ of its original cost. For environmental regulators, it can be realized by cutting down environmental monitoring items, identifying and taking priority-monitoring items or applying for subsidy from Finance Ministry. However, to make monitoring probability down to $1, \mathrm{~F}$ should be reduced to $18 \%$ of its original value which is impossible.

\section{2) Increase fines for over-standard polluters.}

When fines is higher than $28 * 10^{4} \mathrm{CNY}, \mathrm{p} * *$ will be lower than 1 and the $\mathrm{q}^{*} *$ will be higher than 0.89 . Thus, increase $\mathrm{F}$ can help to improve companies' under-standard emission probability and protect local environmental quality.

3) Increase public participation of companies'

production activities, in order to improve the importance of public evaluation for companies.

As long as the importance of public evaluation (Je) rising to $47 \%, \mathrm{p} * *$ can be reduced to less than 1 and the regulatory pressure can be reduce significantly.

4) Increase the public participation of environmental regulators, to improve the importance and objectivity of public evaluation.

According to questionnaires, the importance of public evaluation is $48 \%$. If it can be raised to $60 \%, \mathrm{q} * *$ can be raised to 3.6 and there is no impact on $\mathrm{p}$, which can increase companies' under-standard emission significantly.

It is difficult to achieve the ideal game equilibrium by changing a single parameter, so here we reassign several parameters. For companies, decrease Ce to $90 \%$ of its original value, increase the importance of public evaluation to $45 \%$ and increase $\mathrm{F}$ to $10 * 10^{4} \mathrm{CNY}$. For environmental regulators, decrease $\mathrm{Cg}$ to $90 \%$ of its original value, increase the importance of public evaluation to $50 \%$, and increase the bonus and penalty to $1000 \mathrm{CNY} /$ month respectively as their work assessment system. The reassignments of parameters are summarized in Table IV.

TABLE IV: PARAMETERS AND REASSIGNMENTS OF THE MODEL

\begin{tabular}{ccccc|cccc}
\hline \hline & \multicolumn{3}{c|}{$\begin{array}{c}\text { The shale gas production } \\
\text { company }\end{array}$} & \multicolumn{5}{c}{$\begin{array}{c}\text { The environmental } \\
\text { regulator }\end{array}$} \\
\hline Parameters & $\mathrm{Ce}$ & $\mathrm{Je}$ & $\mathrm{A}$ & $\mathrm{F}$ & $\mathrm{Cg}$ & $\mathrm{Jg}$ & $\mathrm{R}$ & $\mathrm{D}$ \\
Amount & 79 & 36 & 0 & 10 & 58 & 29 & 0.6 & 0.6 \\
$\left(* 10^{4} \mathrm{CNY}\right)$ & & $(45 \%)$ & & & & $(50 \%)$ & & \\
\hline \hline
\end{tabular}

Then a new game equilibrium can be acquired.

$$
\begin{aligned}
\mathrm{p} * * & =(\mathrm{Ce}-2 \mathrm{Je}) /(\mathrm{A}+\mathrm{F})=(79-2 * 36) / 10=0.72 \\
\mathrm{q} * * & =1-(\mathrm{Cg}-\mathrm{R}-\mathrm{D}-2 \mathrm{Jg}) / \mathrm{F} \\
& =1-(58-0.6-0.6-2 * 29) / 10=1.12
\end{aligned}
$$

According to the new game results, the probability of environmental monitoring is 0.72 and the probability of companies' under-standard emission is 1.12 , which indicates that environmental regulators' pressure could be decreased significantly, and development companies' under-standard emission behaviors could be enhanced remarkably. Therefore in the game between environmental regulators and shale gas companies, it needs multi-parameters' synergistic effect to facilitate the equilibrium variation.

\section{ENVIRONMENT MANAGEMENT SUGGESTIONS}

\section{A. Heavy Regulations on Over-Standard Discharge Companies}

The amount of fine can be increased. When $\mathrm{F}$ is higher than 282 thousand CNY, $\mathrm{p}^{* *}$ is less than 1 , while $\mathrm{q}^{* *}$ is higher than 0.88 . Thus, it may help realize the aim of protecting the environment. Besides, subsidies can be given to companies of reaching the standard only. China implements the subsidy policy for the shale gas industry. If we take this measure, $\mathrm{p}^{* *}$ decreases significantly, which means that the regulation pressure can be reduced.

\section{B. Strengthening Public Participation and Opening up More Ways for Public to Participate}

For companies, if the importance of public participation is raised to $48 \%, \mathrm{p}^{* *}$ decreases below 1 , which may reduce regulatory pressure. Likewise, if the importance of public participation is raised to $60 \%, \mathrm{Jg}$ and $\mathrm{q}^{* *}$ reach to 387 
thousand CNY and 3.6 respectively, which indicates that the rate of under-standard discharge of companies would be improved greatly. Therefore, diversified forms should be adopted to strengthen the local public participation. Environmental regulators should force companies to public the quantity and composition of fracturing fluid and make a list of forbidden additives that may cause environmental problems and risks in fracturing fluid.

\section{Implementation of Key Regulations on Water Environment}

Currently, the technology of hydraulic fracturing has been extensively used in the development of shale gas, while this method has some neglected adverse problems, for instance, dissipation of water resources, surface water pollution, groundwater pollution, causing geological disasters. Given the reality that most of shale gas fields is located in remote mountainous areas, which intensifies the difficulty and pressure of environmental supervision, the strategy of key regulations surrounding the water environment should be adopted, as according to American experience, the most important impact of shale gas development activities lies in the water environment. This monitoring tactic can not only control the major risk sources, but also can save cost of environmental regulation and reduce work pressure of monitoring department.

\section{CONCLUSION}

In this paper, we construct a specific game reflecting the decision-making believers of companies and regulators based on an instance. In order to alleviate the pressure of regulation, several measures have been put forward. Future work should consider more parameters, for instance, the pressure of local government and economic development. Besides, the specific quantitative analysis methods of public evaluation and public participation need to support this study. Finally, the sample capacity of questionnaire should be increased.

\section{ACKNOWLEDGMENTS}

We would like to thank Ning Zhang, Jinhua $\mathrm{Li}$ and Chaofan Niu for the data collection.

\section{REFERENCES}

[1] X. Ni, "Encourage private investment to enter in - Accelerate the development of China's shale gas industry," China Economic \&Trade Herald, vol. 33 pp. 21-23, 2012.

[2] T. Coniine, R. Watson, and J. Martin, "Environmental impacts during Marcellus shale gas drilling: Causes, impacts, and remedies," 2012.
[3] B. Andrew, W. H. Jeong, and E. C. Corrie, "Life-cycle greenhouse gas emissions of shale gas, natural gas, coal, and petroleum," Environmental Science \& Technology, vol. 2, p. 46, 2012.

[4] D. Rahm, "Regulating hydraulic fracturing in shale gas plays: The case of Texas energy policy," vol. 5, p. 39, 2011.

[5] S. Xufeng, "High attention on environmental implications of shale Gas exploitation in China," China WTO Tribune, vol. 6, 2012

[6] J. Zhao and L. Senman, "Review on completion fracturing technology for horizontal shale gas well," Natural Gas and Oil, vol. 1, pp 48-51, $102,2012$.

[7] J. Wang and S. Yuan, "Present situation and countermeasures of environment management in shale gas development in China," Environmental Science and Management, 2016.

[8] H. Niu and M. Luo, "Suggestions on environmental management for shale gas exploitation in China," Environmental Impact Assessment, 2017.

[9] S. W. Kou and P.L. Lu, "Atmospheric environmental impact in shale gas exploration, and management experience and enlightenment from the U.S.," Environmental Impact Assessment, 2017.

[10] The Survey Report on Environmental Protection of the phase 1 project of Fuling Shale Gas Field[R], Chongqing Fuling Environmental Protection Bureau, 2017.

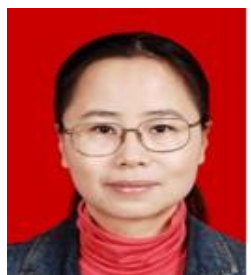

Li Liu was born in Sichuan province of China on March 27 1971. She graduated from Chongqing University in 1992 with the bachelor degree on mining environmental protection, and in 2003 with the master degree on environmental engineering. She finished her another master study at International Institute for Geo-Information Science and Earth Observation in the Netherlands in 2003 with the master degree on urban planning and management. Her research interests are environmental sociology, spatial analysis by GIS, spatial environmental behavior and safety studies. The research fields are mining and resource GIS system, urban spatial safety behavior.

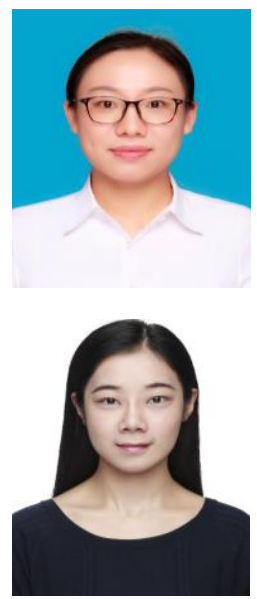

Xiubin Jiang was born in Heilongjiang province of China on July 15 1992. She graduated from Northeast University in 2014 with the bachelor degree on environmental science. Now, she is doing her postgraduate program of environmental engineering in Chongqing University. Her research interest is environmental management.

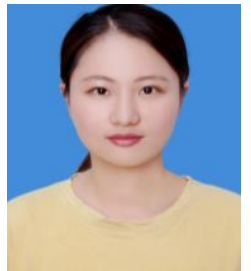

Lu Xinyu was born in Guangxi province of China on Jun 24 1991. She graduated from Minzu University of China in 2013 with the bachelor degree on ecology, and from Chongqing University in 2016 with the master degree on environmental engineering.

Sha Zhou was born in Sichuan province of China on June 19 1994. She graduated from Xihua University in 2016 with the bachelor degree on environmental engineering. She has studied at Chongqing university since 2017 for her master degree on environmental engineering and her research interest is environmental management. 